\title{
Flavobacterium meningosepticum from cases'of meningitis in Botswana and England
}

\author{
S. P. LAPAGE AND R. J. OWEN \\ From the National Collection of Type Cultures, Central Public Health Laboratory, \\ Colindale Avenue, London
}

SYNOPSIS Two strains of Flavobacterium meningosepticum isolated from cases of meningitis are described. One was isolated in Botswana from a man with an aplastic anaemia, the other in the UK from an infant who was probably infected in Bangladesh. The severity of the infection, the characterization of the organism, and the possibility that infection may be found in the UK are discussed.

The name Flavobacterium meningosepticum was originally proposed by King (1959) for a group of strains previously isolated from cases of meningitis in the newborn (Brody, Moore, and King, 1958). Further isolations from similar infections have been described in several parts of the world: Zaire (Buttiaux and Vandepitte, 1966); USA (Cabrera and Davis, 1961; George, Cochran, and Wheeler, 1961; Plotkin and McKitrick, 1960); Israel (Seligmann, Komarov, and Reitler, 1963); Ceylon (Sugathadasa and Arseculeratne, 1963); South Africa (Watson, Krogh, and Jones, 1966); Brazil (Madruga, Zanon, Pereira, and Galvão, 1970); Japan (Yabuuchi, Ohyama, Takeda, Sugiyama, and Kōno, 1970); and India (Agarwal and Ray, 1971). Six serological types of $F$. meningosepticum (A, B, C, D, E, and F) have been described. Of the strains isolated from infections of the newborn, serotype $C$ has been the most common.

F. meningosepticum has occasionally been isolated from adults, chiefly from debilitated patients (King, 1959; Madruga et al, 1970), and from the genitals of adult patients of both sexes suspected of gonococcal infection (Olsen and Ravn, 1971), but the authors in the latter report did not consider that the strains played a pathogenic role. Werthamer and Weiner (1972) reported a case of subacute bacterial endocarditis, caused by $F$. meningosepticum, in a patient with rheumatic heart disease.

This account reports two cases of $F$. meningosepticum infection, one in Botswana in 1969 and the other in a patient in the UK in 1970 who was probably infected in Bangladesh.

Received for publication 19 July 1973.

\section{Case Reports}

\section{CASE 1}

A man aged 19 years from the village of Thamaga in Botswana was admitted to hospital in stupor with epistaxis and a temperature of $102^{\circ} \mathrm{F}\left(38.9^{\circ} \mathrm{C}\right)$. Although initially there was no neck rigidity, lumbar puncture was performed and yielded a clear sterile fluid under normal pressure. The patient's haemoglobin was $27 \%$ and he received a transfusion of 2 pints of blood. Typhoid fever was suspected so treatment with chloramphenicol was begun. However, no organisms were grown from a blood culture and a Widal test did not indicate a Salmonella infection.

In the next few days his temperature rose at times to $105^{\circ} \mathrm{F}\left(40.6^{\circ} \mathrm{C}\right)$ and he developed neck rigidity. A sulphonamide was given and chloramphenicol continued. He showed a tendency towards bleeding and this was treated with prednisone and he was given repeated blood transfusions. Lumbar puncture repeated on the ninth day after admission, when neck rigidity was marked, showed a turbid fluid from which $F$. meningosepticum was isolated. The organism was resistant to a wide range of antibiotics but sensitive to novobiocin. He did not respond to ampicillin treatment and was given neomycin intrathecally and intramuscularly. The meningeal symptoms improved but neomycin had to be discontinued due to swelling and haematomata at the injection sites. His tendency to bleed continued with epistaxis and bleeding from the mucous membranes of the mouth and eyes. Marrow and blood smears taken on the 28th day showed aplastic anaemia. He was then treated with oral novobiocin but failed to 
respond. Methacycline was then tried with no improvement. During his nine-week stay in hospital the patient required transfusion of 15 pints of blood due to repeated haemorrhages. His temperature continued to rise and fall, and his general condition deteriorated. He died after the ninth week but a postmortem examination was not performed.

\section{CASE 2}

A 6-week-old male child, who had come from Dacca in Bangladesh, had been ill since birth and was admitted to hospital with respiratory distress, pneumonitis, and meningitis. He had been given several antibiotics without any substantial response, including penicillin, cloxacillin, gentamycin, and cephaloridine. F. meningosepticum was isolated from the cerebrospinal fluid and was resistant to almost every chemotherapeutic agent used except trimethoprim and sulpha-methoxazole (Septrin) and carbenicillin. Septrin was administered intravenously and intrathecally and the child improved considerably. The mother took the child home from the hospital and his future progress is not known.

\section{Bacteriological Studies}

The two field strains were compared with $F$. meningosepticum NCTC 10016 (serotype A) and NCTC 10585 (serotype B) in a range of morphological, physiological, and biochemical tests by the methods of Cowan and Steel (1965). Antibiotic sensitivity was tested by the use of Oxoid Multodisks, except for polymyxin for which discs were prepared. Slide agglutination tests were made with a 1 in 10 dilution of antisera to $F$. meningosepticum (types A-F). Positive slide agglutination tests were confirmed by tube agglutination. The antisera, supplied by Dr R. E. Weaver, were confirmed in this laboratory as specific for the NCTC deposited serotypes of $F$. meningosepticum (NCTC 10016, 10585-10589, types A-F respectively) by tube agglutination tests. Deoxyribonucleic acid (DNA) was extracted and purified and melting temperatures (Tm) were determined by thermal denaturation following Hill (1968). Base compositions (\% GC) were calculated from melting temperatures in

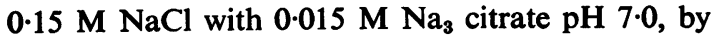
the relation $\% \mathrm{GC}=2.44 \mathrm{Tm}-169.0$.

The organisms were non-motile, Gram-negative rods which measured $1-3 \mu$ by $0 \cdot 6-0 \cdot 8 \mu$ with parallel sides and rounded ends. The colonies on nutrient agar after 24 hours at $37^{\circ} \mathrm{C}$ were circular, $0.5-2.0 \mathrm{~mm}$ in diameter, entire, low convex, opaque, smooth and shiny; they were not pigmented within $24 \mathrm{hr}$, but a pale-yellow coloration was evident after three to four days at room temperature. Pigment production was not enhanced on casein agar, egg-yolk agar or $\square$ blood agar on which medium beta-haemolysis was $\stackrel{0}{F}$ not seen although after a few days some greenish $\frac{\text { ㅇ }}{.}$ coloration and clearing took place. The strains all $\vec{\Rightarrow}$ grew aerobically at 22,30 , and $37^{\circ} \mathrm{C}$, but did not $\stackrel{\circ}{?}$ grow at $44^{\circ} \mathrm{C}$, while growth under anaerobic con- $\frac{}{\square}$ ditions was poor.

The strains gave positive results in the following $\frac{\bar{D}}{\bar{\sigma}}$ tests: presence of catalase and of cytochrome- $\varnothing$

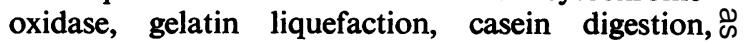
production of phosphatase, hydrogen-sulphide and $\vec{\circ}$

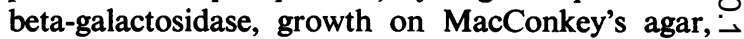
and peptonization of purple milk. Weak production $\vec{\omega}$ of indole was demonstrated after five days in nutrient broth culture by extraction with xylene and the addition of Ehrlich's reagent. Glucose was utilized by oxidation in the O-F test and acid was produced from maltose, mannitol, and lactose in the same medium.

Both field strains and NCTC 10016 partially $ᄋ$ digested Loeffler's serum within 14 days, but NCTC 10585 did not. The strains were sensitive to chlor- 0 amphenicol $(50 \mu \mathrm{g})$, erythromycin $(10 \mu \mathrm{g})$, nalidixic $\stackrel{?}{\circ}$ acid $(30 \mu \mathrm{g})$, novobiocin $(5 \mu \mathrm{g})$, and tetracycline $\frac{O}{0}$ $(50 \mu \mathrm{g})$ but resistant to ampicillin $(25 \mu \mathrm{g})$, nitrofurantoin $(200 \mu \mathrm{g})$, penicillin $\mathrm{G}(1.5$ units), poly- $\overrightarrow{0}$ myxin B (100 units), streptomycin $(25 \mu \mathrm{g})$, and sulphafurazole $(500 \mu \mathrm{g})$. The strain from case ${ }^{\circ}$ gave a positive slide and tube agglutination wi antiserum to serotype $A$ and the strain from case with antiserum to serotype $B$. No reactions were given by these field strains with other $F$. meningo- $\frac{\mathrm{O}}{\Phi}$ septicum antisera.

The DNA base compositions fell within the narrow range of 36.6 to $37.6 \%$ GC (NCTC 10016 , $37.6 \%$; NCTC $10585,36.6 \%$; strains 1 and 2 , $37.4 \%$ ) and are similar to the values for this species reported by Mitchell, Hendrie, and Shewan (1969).

\section{Discussion}

Case 1 provided the first known strain of $F$. meningosepticum to be isolated in Botswana and case 2 the $ᄋ$ first infection with this organism to be reported from Bangladesh, where the infection was probably음 acquired. Greaves (1966) reported two strains of Flavobacterium from clinical material in England, $\infty$ but neither were shown conclusively to be $F$. N meningosepticum nor proved to be pathogenic in the N patients concerned.

In the newborn, Flavobacterium meningosepticum

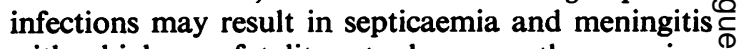
with a high case-fatality rate; however, the organism may be found in the nose and throat of healthy newborn babies during epidemics of meningitis due $-{ }^{-}$ to $F$. meningosepticum (Brody et al, 1958; Cabrera 
and Davis, 1961). The organism is common in the hospital environment and may be found in water (Olsen, 1969).

In adults, infection appears rarely; King, in a personal communication to Olsen, Frederiksen, and Siboni (1965) stated that only four of 68 strains which she examined were isolated from adults. Adult infections appear usually to be mild. King (1959) reported a 69-year-old woman, who had meningitis caused by $F$. meningosepticum but recovered. Olsen et al (1965) and Olsen (1967a, b) described 10 adult patients who were accidentally infected, either by contaminated anaesthetic apparatus or by the intravenous injection of drugs contaminated with $F$. meningosepticum. The patients developed bacteraemia of short duration with pyrexia but all recovered spontaneously. In the case of endocarditis due to $F$. meningosepticum described by Werthamer and Weiner (1972), the patient, a drug addict, recovered.

Case 1 , described in this report, was that of an adult who died with $F$. meningosepticum meningitis, but this was probably only a complication of a severe underlying aplastic anaemia of unknown cause.

Strains of $F$. meningosepticum are usually resistant to a wide range of antibiotics. The poor therapeutic response to those antibiotics to which strains are sensitive in vitro may possibly be due to low concentrations of antibiotics in the cerebrospinal fluid, and therefore intrathecal antibiotics may be indicated in $F$. meningosepticum meningitis. The choice of antibiotic depends on the individual strain and its ability to cross the blood-brain barrier.

Although no cases of $F$. meningosepticum meningitis have been reported in the UK, there seems no a priori reason why they might not appear, and case 2 draws attention to the possibility of imported infection. In view of the gravity of the infection, this possibility should be kept in mind.

We would like to thank Dr R. E. Weaver, Center for Disease Control, Atlanta, Georgia, USA, for the gift of the antisera.

\section{References}

Agarwal, K. C., and Ray, M. (1971). Meningitis in a new born due to Flavobacterium meningosepticum. Indian J. med. Res., 59, 1006-1009.

Brody, J. A., Moore, H., and King, E. O. (1958). Meningitis caused by an unclassified Gram-negative bacterium in newborn infants. Amer. J. Dis. Child., 96, 1-5.

Buttiaux, R., and Vandepitte, J. (1960). Les Flavobacterium dans les méningites épidémiques des nouveau-nés. Ann. Inst. Pasteur, 98, 398-404.

Cabrera, H. A., and Davis, G. H. (1961). Epidemic meningitis of the newborn caused by flavobacteria. I. Epidemiology and bacteriology. Amer. J. Dis. Child., 101, 289-295.

Cowan, S. T., and Steel, K. J. (1965). Manual for the Identification of Medical Bacteria. Cambridge University Press, London.

George, R. M., Cochran, C. P., and Wheeler, W. E. (1961). Epidemic meningitis of the newborn caused by flavobacteria. II. Clinical manifestations and treatment. Amer. J. Dis. Child., 101, 296304.

Greaves, P. W. (1966). Isolation of bacteria resembling Flavobacterium meningosepticum from human material in Britain. Med. Lab. Technol., 23, 115-118.

Hill, L. R. (1968). In Identification Methods for Microbiologists, Part B, edited by B. M. Gibbs and D. A. Shapton. Academic Press, London and New York.

King, E. O. (1959). Studies on a group of previously unclassified bacteria associated with meningitis in infants. Amer. J. clin. Path., 31, 241-247.

Madruga, M., Zanon, U., Pereira, G. M. N., and Galvão, A. C. (1970). Meningitis caused by Flavobacterium meningosepticum. The first epidemic outbreak of meningitis in the newborn in South America. J. infect. Dis., 121, 328-330.

Mitchell, T. G., Hendrie, M. S., and Shewan, J. M. (1969). The taxonomy, differentiation and identification of Cytophaga species. J. appl. Bact., 32, 40-50.

Olsen, H. (1967a). A clinical analysis of 10 cases of postoperative infection with Flavobacterium meningosepticum. Dan. med. Bull., 14, 1-5.

Olsen, H. (1967b). An epidemiological study of hospital infection with Flavobacterium meningosepticum. Dan. med. Bull., 14, 6-9.

Olsen, H. (1969). Flavobacterium meningosepticum isolated from outside hospital surroundings and during routine examination of patient specimens. Acta path. microbiol. scand., 75, 313-322.

Olsen, H., Frederiksen, W. C., and Siboni, K. E. (1965). Flavobacterium meningosepticum in 8 non-fatal cases of postoperative bacteraemia. Lancet, 1, 1294-1296.

Olsen, H., and Ravn, T. (1971). Flavobacterium meningosepticum isolated from the genitals. Acta path. microbiol. scand., 79, 102-106.

Plotkin, S., and McKitrick, J. C. (1966). Nosocomial meningitis of the newborn caused by a Flavobacterium. J. Amer. med. Ass., $198,662-664$.

Seligmann, R., Komarov, M., and Reitler, R. (1963). Flavobacterium meningosepticum in Israel (Letter). Brit. med. J., 2, 1528-1529.

Sugathadasa, A. A., and Arseculeratne, S. N. (1963). Neonatal meningitis caused by new serotype of Flavobacterium meningosepticum. Brit. med. J., 1, 37-38.

Watson, K. C., Krogh, J. G., and Jones, D. T. (1966). Neonatal meningitis caused by Flavobacterium meningosepticum type $F$. J. clin. Path., 19, 79-80.

Werthamer, S., and Weiner, M. (1972). Subacute bacterial endocarditis due to Flavobacterium meningosepticum. Amer. J. clin. Path., $57,410-412$.

Yabuuchi, E., Ohyama, A., Takeda, H., Sugiyama, M., and Kōno, S. (1970). Flavobacterium meningosepticum from neonatal meningitis. Jap. J. Microbiol., 14, 241-242. 